\title{
DETAILED AND HIGHLY ACCURATE 3D MODELS OF HIGH MOUNTAIN AREAS BY THE MACS-HIMALAYA AERIAL CAMERA PLATFORM
}

\author{
J. Brauchle, D. Hein, R. Berger \\ German Aerospace Center (DLR), Institute of Optical Sensor Systems, Berlin, Germany \\ \{Joerg.Brauchle|Daniel.Hein| Ralf.Berger\}@DLR.de
}

KEY WORDS: 3D Model, Himalaya, MACS, Aerial Camera, DEM, Mt. Everest, glacier mass balance, HDR

\begin{abstract}
:
Remote sensing in areas with extreme altitude differences is particularly challenging. In high mountain areas specifically, steep slopes result in reduced ground pixel resolution and degraded quality in the DEM. Exceptionally high brightness differences can in part no longer be imaged by the sensors. Nevertheless, detailed information about mountainous regions is highly relevant: time and again glacier lake outburst floods (GLOFs) and debris avalanches claim dozens of victims. Glaciers are sensitive to climate change and must be carefully monitored.

Very detailed and accurate 3D maps provide a basic tool for the analysis of natural hazards and the monitoring of glacier surfaces in high mountain areas. There is a gap here, because the desired accuracies are often not achieved.

It is for this reason that the DLR Institute of Optical Sensor Systems has developed a new aerial camera, the MACS-Himalaya. The measuring unit comprises four camera modules with an overall aperture angle of $116^{\circ}$ perpendicular to the direction of flight. A High Dynamic Range (HDR) mode was introduced so that within a scene, bright areas such as sun-flooded snow and dark areas such as shaded stone can be imaged. In 2014, a measuring survey was performed on the Nepalese side of the Himalayas. The remote sensing system was carried by a Stemme S10 motor glider. Amongst other targets, the Seti Valley, Kali-Gandaki Valley and the Mt. Everest/Khumbu Region were imaged at heights up to 9,200 m. Products such as dense point clouds, DSMs and true orthomosaics with a ground pixel resolution of up to $15 \mathrm{~cm}$ were produced. Special challenges and gaps in the investigation of high mountain areas, approaches for resolution of these problems, the camera system and the state of evaluation are presented with examples.
\end{abstract}

\section{INTRODUCTION}

Digital terrain models form the basis for a series of analyses in environmental monitoring, natural hazards and as a simulation database. High mountain regions play a major role, as indicated by a series of geological and climatic processes (Lemke et al., 2007). Multi-temporal measurement data acquisition by remote sensing is an important environmental monitoring tool for determining the change in glacier extent and volume (Abermann et al., 2010; Kääb 2002; Bolch et al., 2011). In areas such as the Andes or the European Alps, aerial cameras and laser scanners are used in addition to satellite-based systems (Bamber \& Rivera, 2007; Quincey et al., 2005). In other areas such as the high areas of the Himalayas, only satellite-based systems are used; aerial cameras as indicated in (Müller et al., 2014) are not used. Solely in 1984 was a WILD RC30 analogue aerial camera flown over the area of Mt. Everest in a Learjet 35 at an altitude $^{(1)}$ of 13,100 $\mathrm{m}$ (Altherr \& Grün, 1990). This set of data yields, for a narrowly limited area, important information for time series analyses. Nevertheless, the geometric resolution of $0.5 \mathrm{~m}$ horizontal and $15 \mathrm{~m}$ in the DTM plus the 8 bit radiometric resolution (Bolch et al., 2011, Pieczonka et al., 2011) are now exceeded by satellite-based systems (Poli et al., 2010; Berthier, 2014). For selected areas, attempts were made to perform survey flights over mountain glaciers at approximately 4,300 $\mathrm{m}$ altitude using unmanned systems (Immerzeel et al.,

\footnotetext{
(1) The altitude data in this paper are, if not otherwise stated, relative to sea level (a.s.l.).
}

2014). To do so, the ground personnel had to remain in the survey area.

Investigations into the performance capability of optical remote sensing systems indicate that enormous progress has been made over the last 20 years. The geometric as well as the radiometric resolution has been increased and satellite-based data are made available to scientists, e.g. SPOT through the ISIS program of the French Space Agency, CNES.

However, in some situations more information is desirable or absolutely necessary. This includes, for example, radiometric resolution without any saturation zones, the modelling of steep slopes without degradation of the quality of the digital elevation model (DEM) and the monitoring of glaciers even in the highest regions of the world with a ground sampling distance (GSD) of $<<30 \mathrm{~cm}$. At the DLR Institute of Optical Sensor Systems, approaches have been developed to show how these targets can be achieved with the aid of a new aerial camera and further developed evaluation and visualisation methods. This paper is derived from these approaches. Moreover, the camera system is introduced and the current state of the evaluation is presented by way of example.

\section{SPECIAL REQUIREMENTS IN HIGH MOUNTAINS}

\subsection{Orography}

A major challenge in optical remote sensing is the modelling of severely inclined structures with a gradient $>40^{\circ}$ (Müller et al., 2014). The quality of useful data is degraded due to the observation geometry. If the angle of incidence on the surface is 
too low (vertical shot or low off-nadir angle), the ground pixels become greater. A nearly linear relationship between the precision of a DEM and the gradient has been identified (Toutin, 2002). In high mountain areas, there are slopes that in part include sections with vertical gradients, which greatly reduces the precision of the DEM. Satellite-based camera systems offer (multi)stereo functionalities by swivelling of the optics. Table 1 lists the GSDs of standard high resolution remote sensing satellites. However, the GSD increases as the off-nadir angle increases. Also, at large angles of up to $45^{\circ}$, an additional effect may arise whereby surrounding elevated points hide the target area.

\begin{tabular}{|l|c|}
\hline Satellite & GSD pan, nadir \\
\hline WorldView-1 & \multirow{2}{*}{$0.5 \mathrm{~m}$} \\
\cline { 1 - 1 } WorldView-2 & \multirow{2}{*}{0.5} \\
\cline { 1 - 1 } Pléiades & \\
\cline { 1 - 1 } GeoEye-1 & $0.3 \mathrm{~m}$ \\
\hline WorldView-3 & $0.6 \mathrm{~m}$ \\
\hline QuickBird & $0.8 \mathrm{~m}$ \\
\hline Cartosat-2B & $0.8 \mathrm{~m}$ \\
\hline IKONOS & $1.5 \mathrm{~m}$ \\
\hline SPOT-6 \& 7 &
\end{tabular}

Table 1. GSD of high resolution remote sensing satellites; sources: respective data sheets of the manufacturers/operators

In urban areas in particular, the precision of high resolution satellite DEMs falls due to disparities in the stereo image pairs. For GeoEye-1, WorldView-2 and Pléiades-1A, RMSE values between 6.1 and $8.5 \mathrm{~m}$ have been determined (Poli et al., 2014). In high mountain areas, the topographical height differences are increased by an order of magnitude, so that the precision is further reduced. On the other hand, homogeneous structures such as glaciers can be more accurately modelled. A vertical precision of glacier DEMs in high mountains with an SD between 0.51 and $1.26 \mathrm{~m}$ is achieved with the aid of Pléiades stereo image pairs (Berthier et al., 2014). For more inclined structures and vegetation $\pm 3 \mathrm{~m}$ has been determined (Stumpf et al., 2014).

Using airborne systems, the high mountain target area can be imaged from a reduced distance, so that GSDs, and thus the resolution of the DEM, of the order of a few centimetres can be achieved. Standard aerial cameras have maximum off-nadir fields of view of $\alpha / 2=27^{\circ}$ (ADS80, RC30, UltraCam Hawk, DMC IIe) to $\alpha / 2=36.5^{\circ}$ (UltraCam Falcon), so that on steep slopes the improvement in the GSD remains limited. For some time now, diagonally orientated cameras have been available, e.g. UltraCam Osprey, IGI DigiCAM and MIDAS five. Most of them offer an off-nadir shift of $45^{\circ}$. Such systems weigh several dozen kilograms. They are designed for aerial photography aircraft with a floor hatch and are compensated for roll, pitch and yaw using a stabilisation platform. Aircraft capable of carrying such systems must operate at a safe distance from the ground. Strong structured terrain then results in very large differences in the GSDs when imaging from the bottom of a valley to a mountain ridge.

\subsection{Radiometry}

Due to the rarefied atmosphere in high mountain areas, scatter and absorption of light is greatly reduced. Moreover, high mountains and deeply carved valleys result in large, very dark areas of shadow. It often occurs that within short distances extremely light areas, such as sunlight flooded glaciers or snow surfaces, lie alongside extremely dark areas such as shaded dark stone or a narrow valley. The result of this is that an optical sensor must record a scene with an extraordinarily wide radiometric dynamic range.

Current remote sensing systems reproduce the visible light spectrum with a range between 11 and 13 bits; Table 2 summarises a number of systems. Under normal circumstances, imaging with 10-12 bits is adequate. By contrast, it is apparent that in high mountain regions such as the Himalayas, such a dynamic range is not always sufficient. In satellite images with 12 bit resolution $10 \%$ of pixel saturation occur (Berthier et al., 2014). This can be countered by the use of special imaging plans with reduced sensor amplification. Such types of investigations were performed for 8 bit imagers (e.g. SPOT1-5, ASTER) (Korona et al., 2009; Raup et al., 2000). The result of this is that snow and ice areas can be radiometrically resolved, but the dark areas of the scene can no longer be portrayed.

\begin{tabular}{|c|c|c|}
\hline $\begin{array}{c}\text { Remote sensing } \\
\text { system }\end{array}$ & $\begin{array}{c}\text { Dynamic } \\
\text { range }\end{array}$ & Source \\
\hline $\begin{array}{l}\text { Microsoft } \\
\text { UltraCamD }\end{array}$ & 13 bit & \multirow{3}{*}{ Honkavaara \& Markelin, 2007} \\
\hline Intergraph DMC & 12 bit & \\
\hline Leica ADS40 & 13 bit & \\
\hline $\begin{array}{l}\text { Microsoft } \\
\text { UltraCam-Xp, } \\
\text { UltraCam } \\
\text { Falcon }\end{array}$ & 12 bit & $\begin{array}{l}\text { Technical specs of } \\
\text { UltraCamXp (2008) and } \\
\text { UltraCamFalconP (2013) }\end{array}$ \\
\hline $\begin{array}{l}\text { Microsoft } \\
\text { UltraCam-X }\end{array}$ & $<13$ bit & Schneider \& Gruber, 2008 \\
\hline $\begin{array}{l}\text { High resolution } \\
\text { satellite imaging }\end{array}$ & 11 bit & Jacobsen, 2005 \\
\hline
\end{tabular}

Table 2. Radiometric resolution of common remote sensing systems (choice)

We are not aware of any available remote sensing sensors that have a sufficiently wide dynamic range to be able to meaningfully radiometrically image all occurring lighting situations within a scene.

\section{MEASURING SYSTEM}

To be able to generate a clear improvement in DEM resolution in heavily structured terrain and to improve the radiometric dynamic range, a new remote sensing system was developed. The aircraft described in section 3.5 was identified as a carrier that can operate reliably in the high Himalayas test area. The aim was to fulfil the following points:

- The measuring instrument functions operationally under the prevailing conditions of use (see section 3.3). 
- To be able to create DEMs/DSMs of higher resolution than has been possible up until now. This also applying for slopes with an inclination of more than $45^{\circ}$.

- DEMs are accurate and precise, i.e. they have an uncertainty in respect of geographical position and NMAD (normalised median absolute deviation) that is demonstrably as small as possible.

- A DEM is to be generated for every part, even the smallest, of a target region.

- The radiometric interpretability is increased.

Based on the latest progress in the manufacture of chips for digital imaging sensors in respect of geometric and radiometric resolution, noise performance, saturation characteristics and new photographic interpretation methods, it was decided to develop an aerial camera with RGB and NIR spectra. Highly resolved DEMs, RGB textures and NIR signatures can be derived from its images. Alongside automated change detection such as glacier volumes and tectonic movements, classifications can be performed, e.g. water and vegetation masking.

The sensor system was designed based on MACS aerial cameras (Modular Airborne Camera System) (Lehmann et al., 2011). Multiple individual sensor modules were implemented taking into consideration the conditions presented in sections 2 and 3.3 .

\subsection{Imaging geometry}

Two RGB camera modules were set up perpendicular to the direction of flight each at an off-nadir angle of $36^{\circ}$. The gap between them was filled by a further, identical camera module. An NIR module was likewise positioned for vertical viewing. This results in a total aperture angle for the RGB spectrum of $\alpha=116^{\circ}$ perpendicular to the direction of flight. When flying parallel to the slope, the flank of the mountain is ideally imaged at a perpendicular angle so that optimum ground pixel resolution is attained. Projective distortion, which occurs with oblique shots in level terrain by changing the image scale within an image, is reduced here and in the optimum case, shots perpendicular to the slope, is equivalent to an ideal nadir aerial photograph. Forward/backward viewing directions are not used, because such images would not offer significant advantage for the intended slope-parallel surveying flights. Aerotriangulation (AT) is based on the perpendicularly aligned camera. The outer orientation of the oblique images is determined using the reference orientation method (Wieden \& Stebner, 2013).

\subsection{High Dynamic Range (HDR)}

The expected dynamic range was countered by use of a High Dynamic Range (HDR) mode. High frequency exposure bracketing was implemented. With four commercial camera modules operated in parallel we achieved a continuous frame rate of 4.4 fps for each camera module. With three-stage HDR operation, that is three different integration times, the frame rate was $3.3 \mathrm{fps}$ (per exposure time $1.1 \mathrm{fps}$ ). That was sufficient to achieve a longitudinal overlap of approximately $90 \%$ per exposure time under the planned mission conditions of $1,000 \mathrm{~m}$ above ground and $180 \mathrm{~km} / \mathrm{h}$ airspeed. Thus from the geometrical point of view, at a frame rate of $1.1 \mathrm{fps}$, there was sufficient longitudinal overlapping for stereoscopic imaging. Using the HDR approach, the possible dynamic range of the imaging should be increased from approximately 12 to 16 bits.

\subsection{Conditions of use}

Use of the measuring instrument was to be possible in the open air at altitudes up to $9,000 \mathrm{~m}$. The photogrammetric measurement reliability had to be ensured in spite of low pressure and temperatures. Camera functioning was tested in a vacuum chamber at a pressure of down to $150 \mathrm{mbar}$, which corresponds to an equivalent altitude of approximately $20,000 \mathrm{~m}$. The objectives were constructed using certain aspects of space-proof manufacturing because air temperatures below $-30{ }^{\circ} \mathrm{C}$ were to be expected. Amongst other things, the lens groups were contained in a single lens tube and a fixed aperture was integrated. The objectives can be actively thermally controlled.

The main computer is specified for an altitude of $>18,000 \mathrm{~m}$. The data storage unit is designed as a swap module and can be exchanged for a new module within a matter of minutes, so that the aircraft can start its next mission and the already collected data can be sorted and/or backed up.

\subsection{Aerial camera}

Figure 1 shows the MACS-Himalaya aerial camera. The technical data are summarised in Table 3. The sensor unit comprises the four camera modules which are held and directed by a bridge. Within the scope of subsequent scientific surveys, this bridge can be rotated vertically through $90^{\circ}$, which, for example, enables the imaging and investigation of forward/backward views. A differently designed bridge enables the carrying of sensors necessary for a particular task, e.g. a hyperspectral apparatus or thermal infrared sensor. Figure 2 shows an individual sensor module. Figure 3 shows the sensor head with four sensor modules, of which two are inclined at $\pm 36^{\circ}$ perpendicular to the direction of flight.

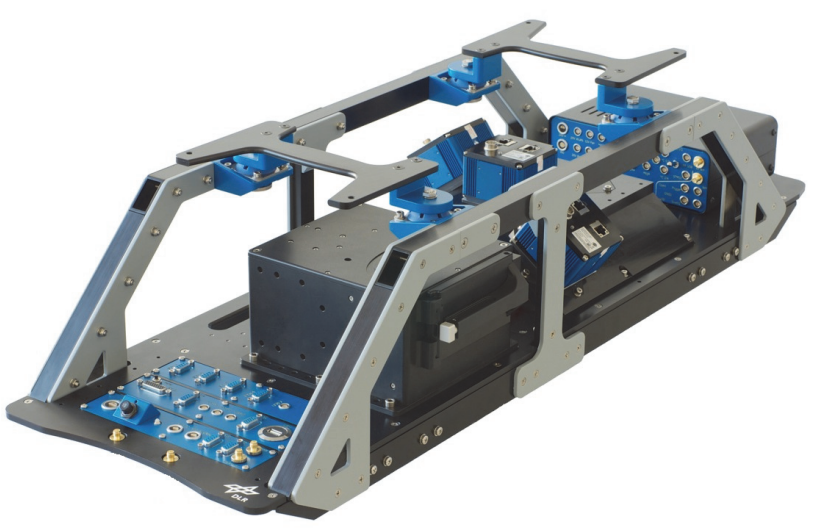

Figure 1. MACS-Himalaya aerial camera 


\begin{tabular}{|c|c|}
\hline Imaging sensors & $\begin{array}{l}\text { Kodak KAI-16070 Bayer CCD, } 4864 \text { x } \\
3232 \text { pixels, } 7.4 \mu \mathrm{m} \text { pixel pitch, } 14 \text { bit } \\
\text { ADC, electronic shutter }\end{array}$ \\
\hline $\begin{array}{l}\text { Camera } \\
\text { arrangement }\end{array}$ & $\begin{array}{l}\text { 1x RGB }+1 x \text { NIR; orientation: } \\
Z_{\text {Aircraft }} \text { positive } \\
2 x \text { RGB; orientation: } \\
\text { lateral oblique } \pm 36^{\circ} \text { left/right }\end{array}$ \\
\hline GSD & $15 \mathrm{~cm} @ 1000 \mathrm{~m}$ distance to ground \\
\hline $\begin{array}{l}\text { Radiometric } \\
\text { resolution }\end{array}$ & $\begin{array}{l}12 \text { bit per channel, } 15 \text { bit aspired with } \\
\text { HDR }\end{array}$ \\
\hline Focal length/IFOV & $50 \mathrm{~mm}$ each camera $/ 0.14 \mathrm{mrad}$ \\
\hline FoV total $(\alpha)$ & $\begin{array}{l}27^{\circ} / 116^{\circ} \mathrm{RGB} \text { (along-track/cross-track) } \\
27^{\circ} / 39^{\circ} \mathrm{NIR}\end{array}$ \\
\hline Image rate & $\begin{array}{l}4 \text { fps max. } \\
3.3 \text { fps with } 3 \text {-step HDR }\end{array}$ \\
\hline $\begin{array}{l}\text { Direct } \\
\text { georeferencing }\end{array}$ & $\begin{array}{l}\text { Post-processed L1/L2 GPS/GLONASS, } \\
\text { mid-cost INS (Novatel SPAN-CPT) }\end{array}$ \\
\hline Computer & Core i7, Linux, 2TB SSD \\
\hline On-board recording & $\begin{array}{l}22,000 \text { images for each sensor per data } \\
\text { cartridge }\end{array}$ \\
\hline Auxiliary devices & $\begin{array}{l}\text { Flight guidance/operator system,temp. } \\
\text { and humidity logging, second L1/L2 } \\
\text { GNSS receiver }\end{array}$ \\
\hline Dimensions & $950 \times 300 \times 280 \mathrm{~mm}^{3}(\mathrm{~L} \times \mathrm{W} \times \mathrm{H})$ \\
\hline Weight & $23 \mathrm{~kg}$ \\
\hline Power consumption & 120 W typ. @28 VDC \\
\hline Temperature min. & $-35^{\circ} \mathrm{C}$ tested operation \\
\hline Altitude & $>9,000 \mathrm{~m}$ tested operation \\
\hline
\end{tabular}

Table 3. Technical data of the MACS-Himalaya aerial camera

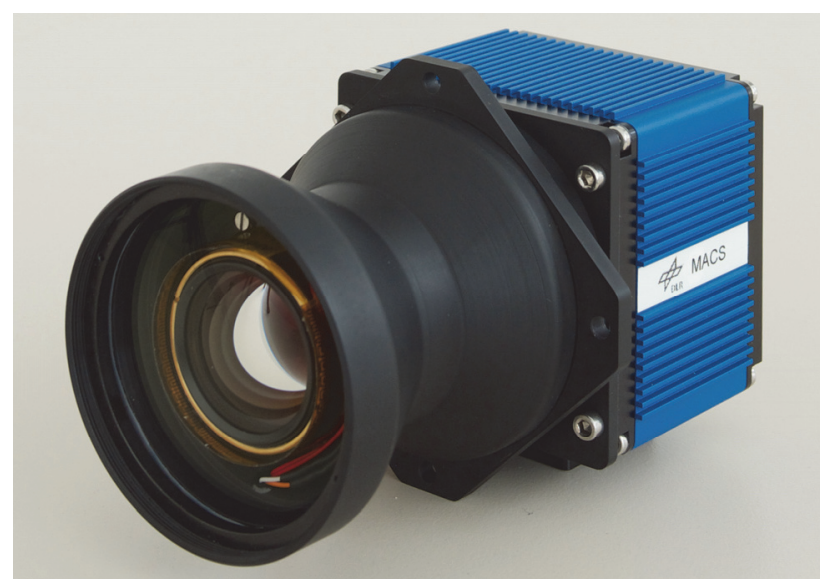

Figure 2. One of three RGB sensor modules
The inner orientation of each sensor module was determined using coded target markers using a spatial control point array and verified by GCPs in the covered test areas as well as followup measurements. Radiometric correction is implemented by determination and application of the parameters for dark signal non uniformity (DSNU) and photo response non uniformity (PRNU) for each sensor module.

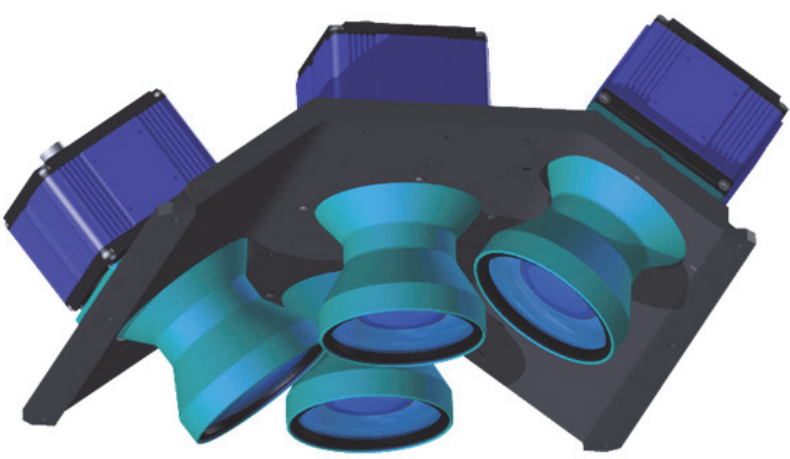

Figure 3. Sensor head with the Himalaya expedition configuration (illustration). The footprint of the bridge is $255 \times 255 \mathrm{~mm}^{2}$

The instrument is connected to the aircraft via a mechanical damping system, whereby two cameras (RGB and NIR) are aligned with the aircraft $\mathrm{Z}$-axis and two cameras have a transverse view being rotated about the aircraft's longitudinal Xaxis (definition of the coordinate system according to DIN 9300 and ISO 1151). A stabilisation platform was not necessary because of the large longitudinal overlapping of the images and the wide cross-track field of view. The cameras follow the roll movement of the aircraft. In addition this enables to record extremely steep slopes and ridges during turning manoeuvres as in this case the camera looks up to the horizon. This method can be particularly worthwhile for valley ends because in this way the slope-parallel flight is continued without interruption. The photogrammetric processing chain for such uncommon image blocks is to be adapted.

\subsection{Carrier aircraft}

The camera system was optimised for use on a two-seater motor glider of type Stemme S10-VTX (Figure 4). This aircraft is suitable for testing the MACS remote sensing system. There is adequate space in external underwing pods. In mountain ranges, the aircraft is suitable for flying along contour-hugging paths with extremely low turn radii, which enables almost any trajectory including relatively close to the slope.

Nevertheless, for experimental work in high mountain areas, safety aspects play a dominant role. In the event of engine damage, the aerodynamic quality, with a glide number of 1:50 comes into play, i.e. in still air, the aircraft loses only $1 \mathrm{~km}$ height over a $50 \mathrm{~km}$ distance. Even in the most remote survey flight area of the Himalayas, it is ensured that an emergency landing strip can be reached. Due to its engine turbo charging, the aircraft can achieve flying altitudes of more than 9,000 m, which was important for testing of the measuring system. An oxygen positive pressure system was installed for the pilots. 
The measuring equipment was installed in one of two unpressurised external pods beneath a wing and had a clear view through an opening in the bottom of the pod.

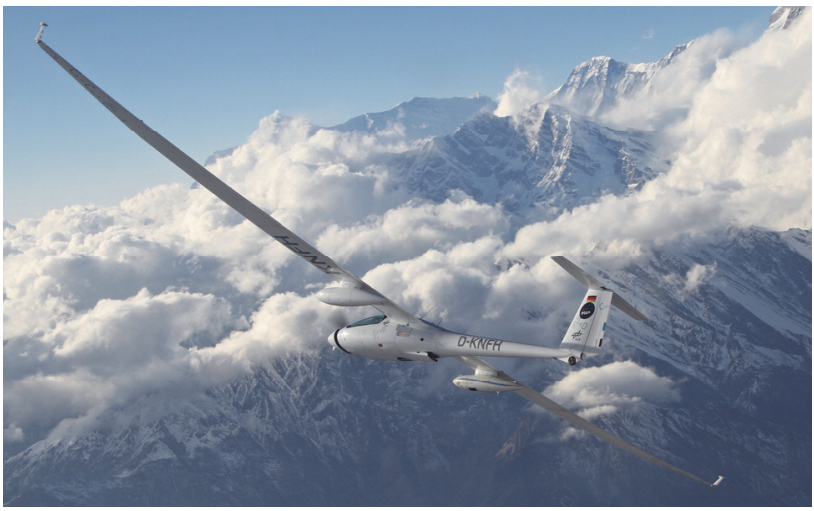

Figure 4. Stemme S10-VTX motorglider during a test flight in a high mountain area. The aerial camera is placed in the right underwing pod.

\section{MEASUREMENT SURVEY}

The system was tested and optimised by test flights in urban areas and in the European Alps. In January 2014, as part of an interdisciplinary expedition, a high mountain survey was performed in Nepal (Heise et al., 2014). Selected areas were investigated in respect of specific questions. In this respect, the aim was on the one hand to empirically investigate the potential of the concepts described in sections 3.1 and 3.2 and on the other hand to obtain scientifically relevant data records which, after evaluation, could be used for various applications.

\section{- Seti Valley:}

With slope gradients $>70^{\circ}$ in some areas and a typical bellshaped valley end, this varied region is suitable for taking oblique shots of steep structures by flying parallel to the slopes and performing appropriate turning manoeuvres. The region is geomorphologically interesting and the start point for GLOFs and moraines (Schwanghart 2014; ICIMOD 2011; Bhandary 2012). Ground-based fieldwork is scarcely possible here due to the inhospitable conditions. A detailed DEM together with vegetation classification could facilitate realistic flooding simulations and enable improved identification of geological movement patterns.

\section{- Kali-Gandaki Valley:}

Due to its extent, the valley is suitable for testing geometrical camera properties using a wide area control point array. With a length of more than $50 \mathrm{~km}$ and a valley bottom in an altitude range between $1,100 \mathrm{~m}$ and $3,300 \mathrm{~m}$, altitude-dependent camera changes can be identified in a ground-parallel flying pattern. GCPs on both sides on the slopes enable validation of the oblique cameras.

\section{- Rikha-Samba Glacier:}

Fresh snow enabled the imaging of this remote glacier under conditions representing highly radiometrically homogeneous surface properties. The performance of the camera and processing chain for glacier monitoring could be checked. For this purpose, radiometrically wellilluminated aerial photographs must be captured to enable creation of a DEM of the entire glacier. The glacier was to be imaged with a GSD of approximately $20 \mathrm{~cm}$.

\section{- Khumbu Glacier:}

It should be possible to create a DEM for the world's highest glacier (4,900 $\mathrm{m}$ to $7,600 \mathrm{~m})$ which can then be used for environmental monitoring.

\section{- Mt. Everest:}

The peak of Mt. Everest represents the highest possible target for remote sensing. The Yellow Band is a distinctive feature. It is located on a gradient of approximately $50^{\circ}$. A high resolution colour $3 \mathrm{D}$ model of the south flank was to be generated with a $\mathrm{GSD}<20 \mathrm{~cm}$. Among others, aim of acquiring this target was to evaluate the overall system function and measurement accuracy of the aerial camera from altitudes of around 9,000 m.

These five target areas were acquired within six days. An additional target was the photographing of the old town of Kathmandu with a GSD of approximately $12 \mathrm{~cm}$. The NIR camera was deactivated from the fourth day due to partially unreliable behaviour so that NIR data are not available for all areas. The maximum flying altitude reached was slightly above $9,200 \mathrm{~m}$. The minimum temperature was less than $-35^{\circ} \mathrm{C}$ during the surveying flight over Mt. Everest. On this day, the starting and landing temperatures were $21^{\circ} \mathrm{C}$ and $18{ }^{\circ} \mathrm{C}$ respectively so that the air humidity in the pod reached $100 \%$. Figure 5 shows a survey flight over the Kali-Gandaki Valley from an altitude of $4,800 \mathrm{~m}$.

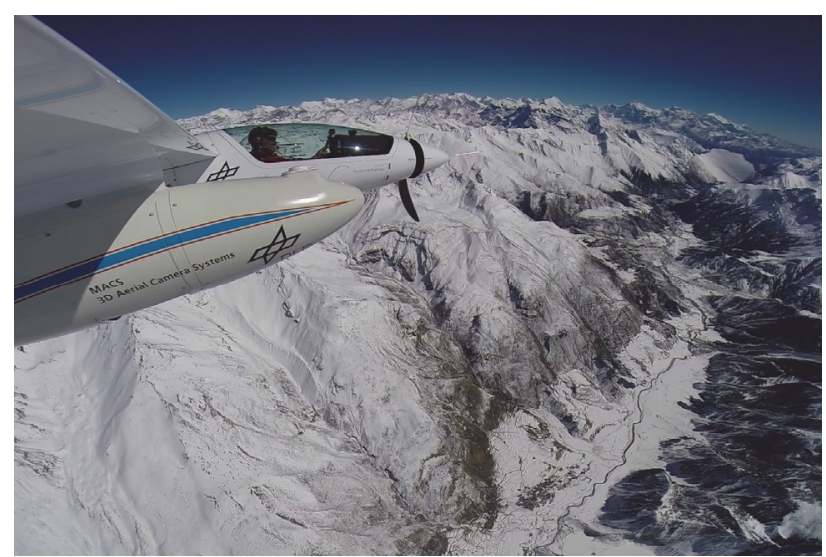

Figure 5. The Kali-Gandaki Valley survey

\section{STATUS OF EVALUATION}

All photographs taken could be interpreted and directly geocoded. In a first step, images of the regions Kali-Gandaki Valley and Khumbu Glacier/Mt. Everest were aero-triangulated and visualised using DSMs. The partially spiral-shaped flight trajectories required modified methods to implement the oblique images. Figure 6 shows an excerpt of a model in which the Yellow Band and peak of Mt. Everest are apparent. The GSD on the flank is approximately $15 \mathrm{~cm}$ in spite of the slope of circa $50^{\circ}$. The Khumbu Glacier was imaged and modelled with a GSD between 20 and $30 \mathrm{~cm}$. 


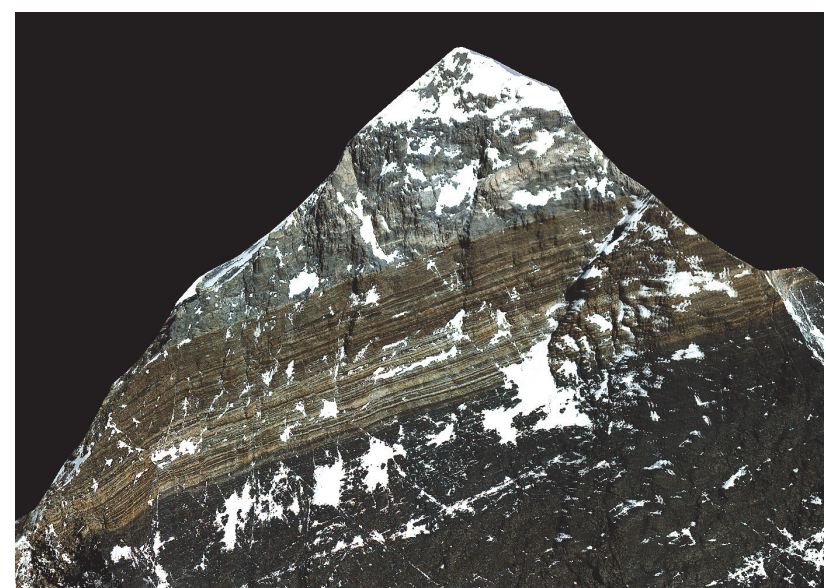

Figure 6. The southern flank of the Mt. Everest's summit with a GSD of circa $15 \mathrm{~cm}$ (3D point cloud snapshot).

\subsection{Geometrical aspects}

The inner orientation of the sensor modules was re-determined and checked using a spatial control point array after the measurement survey. As part of the geodetic measurement series more than 100 GCPs were measured in the Kali-Gandaki Valley, Kathmandu and Khumbu Valley regions. An altitude range from $1,100 \mathrm{~m}$ to $5,550 \mathrm{~m}$ was covered with an as uniform as possible distribution in the respective areas. The geometric evaluation of the aerial photographs is not yet completed. After completion of this phase, the system can be qualitatively described and the accuracy of the DEMs, especially of the Khumbu Glacier, determined. Statements in this respect are to be published in the near future.

\subsection{Oblique views}

The high transverse inclination angle of the camera combined with special flying manoeuvres by the carrying plane deliver perspectives of steep slopes as can be seen in Figure 7. An enlarged excerpt of this image is shown in Figure 8. Areas of the image show nearly vertical structures at an altitude of approximately $5,000 \mathrm{~m}$ in the Upper Seti Valley. The GSD on this slope is approximately $12 \mathrm{~cm}$. The photograph was taken from an altitude of $5,700 \mathrm{~m}$ while in a left curve manoeuvre with a roll angle of $-37.8^{\circ}$. The adjoining photographs are contiguous and yield a gap-free image block. Through the use of such aerial photographs, it should be possible to model the Upper Seti Valley in detail. The aircraft was flown at roll angles of more than $40^{\circ}$. In this way, the camera obtained perspectives extending $75^{\circ}$ off-nadir.

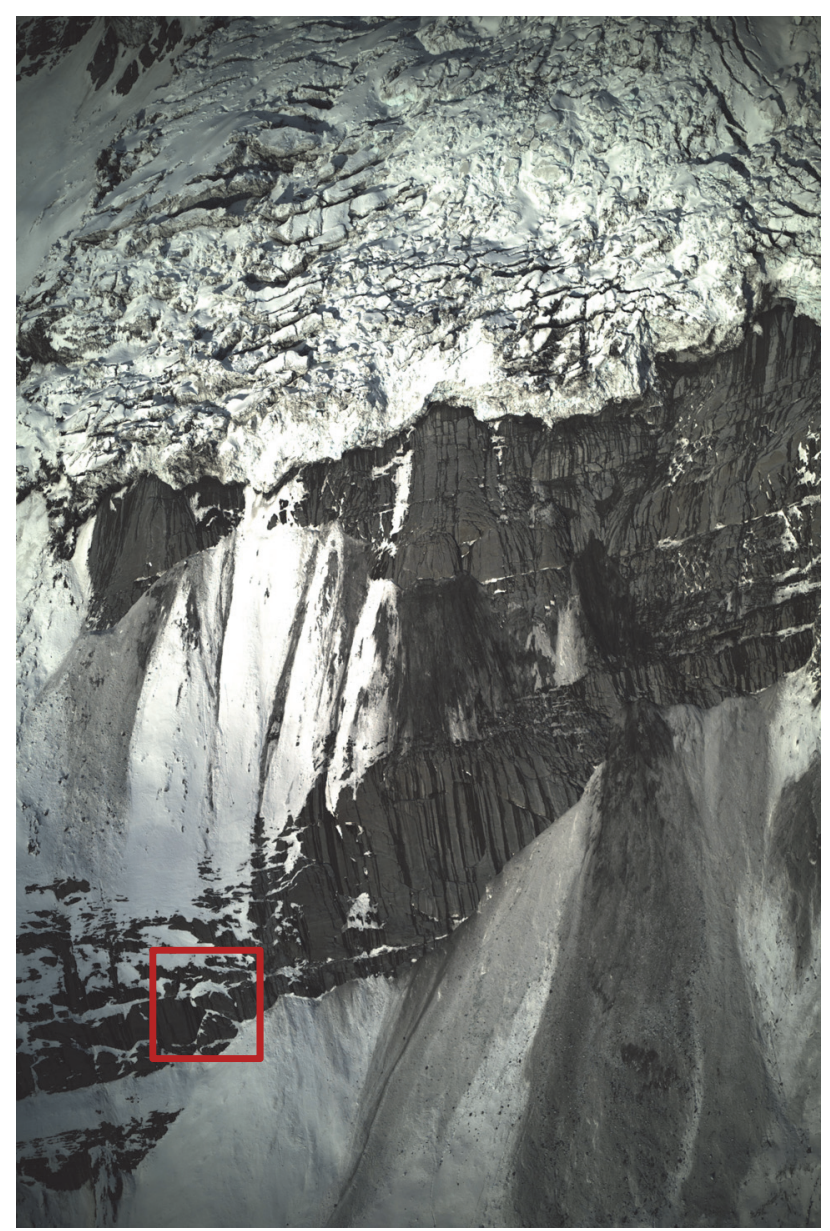

Figure 7. Single image of a steep slope and icefields in the Upper Seti Valley. Position at the time of exposure was $28.549747^{\circ} \mathrm{N} / 84.039636^{\circ} \mathrm{E} / 5,700 \mathrm{~m}$ altitude with an off-nadir angle of $73.8^{\circ}$. The red rectangle indicates the extent of Figure 8

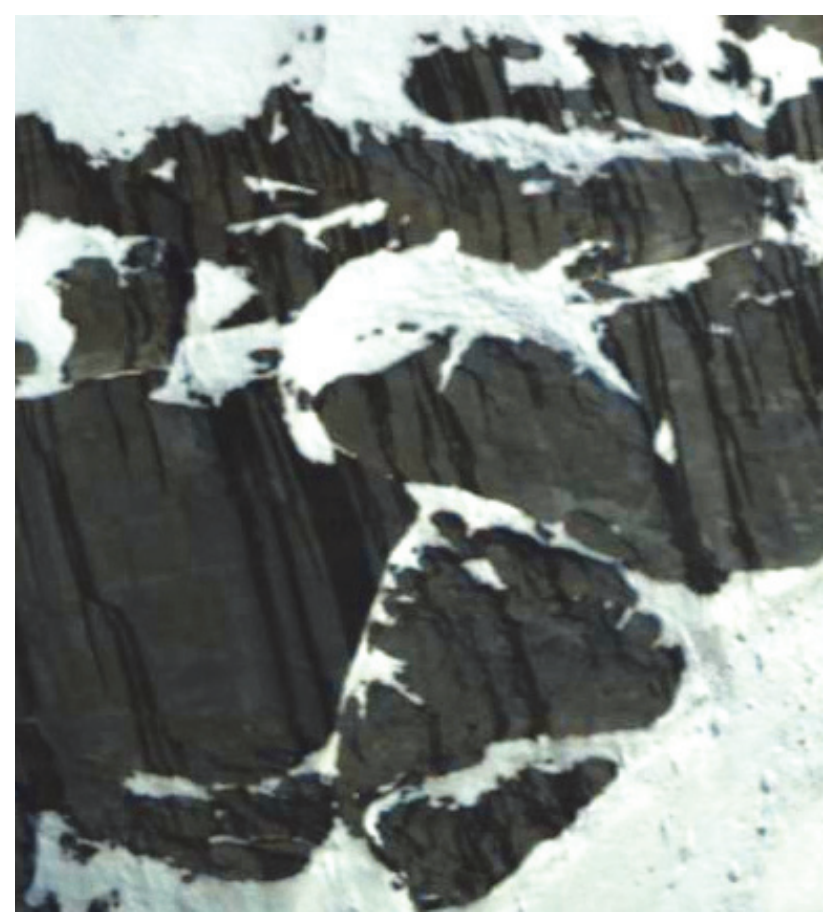

Figure 8. Detail of Figure 7 with a GSD of circa $12 \mathrm{~cm}$ on a steep slope 


\subsection{High Dynamic Range (HDR)}

The analysis of the photographs showed that a 12 bit dynamic range is often insufficient for the imaging of mountainous scenes under all lighting conditions. Even achieving the minimised rate of over- and undershots (optimum integration time) for the scene in question, surfaces are either over- or under-exposed. An example is shown in Figure 9 which shows a series of three different exposure times. Several integration times are necessary to obtain interpretable measuring data for all areas of the scene. Known methods of HDR image creation such as exposure blending cannot be used because, amongst other reasons, the outer orientation is different for every image. The automated, photogrammetrically correct synthesis of the photographs is currently being investigated and will be published shortly.
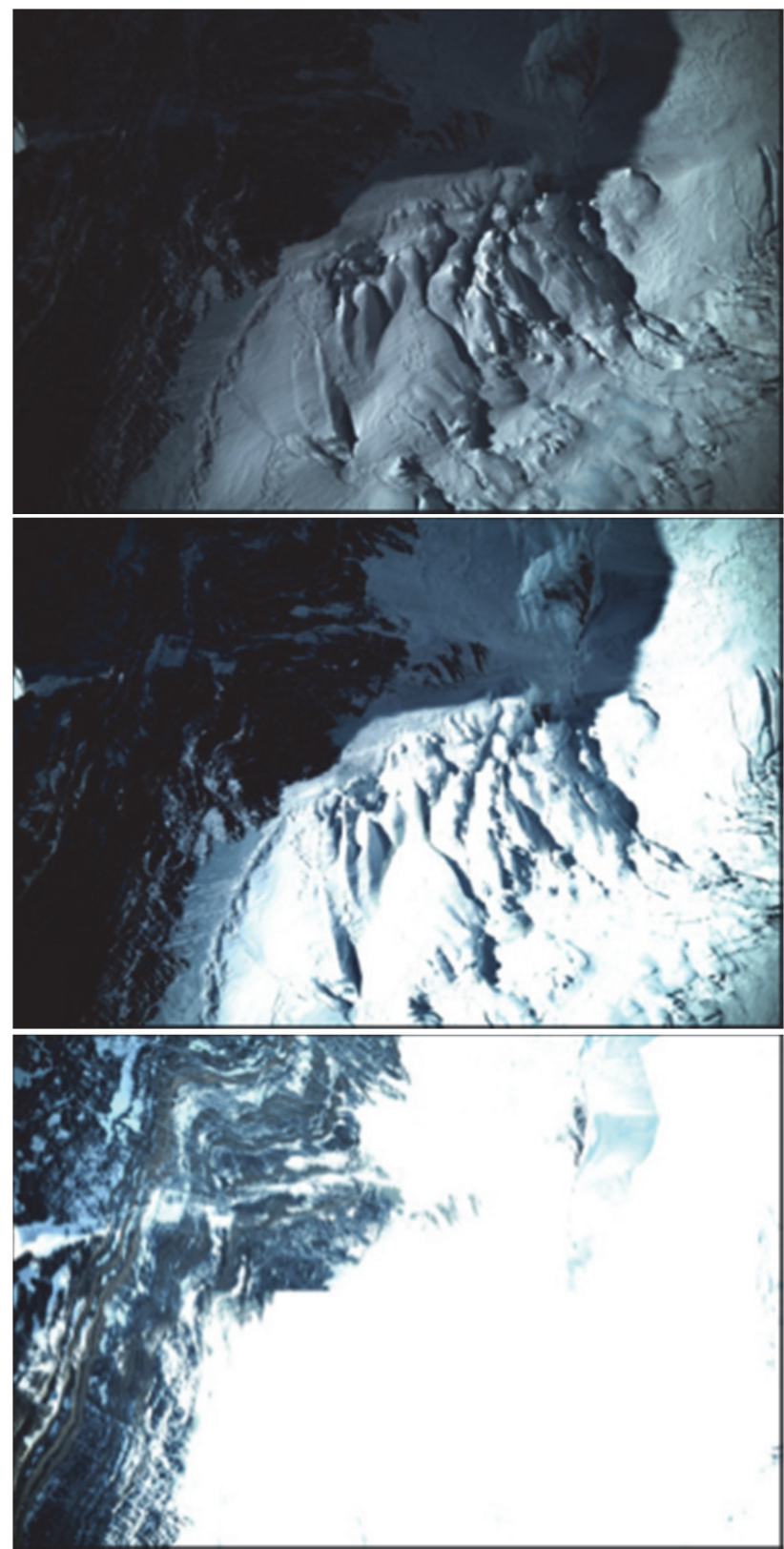

Figure 9. High contrast scene, a series of consecutive 12 bit aerial photos with different integration times. All three images have to be considered to reproduce all areas.

\section{SUMMARY}

It has been shown that it is very difficult to measure high mountain areas using optical remote sensing systems. The orographically highly structured terrain and the enormous variations in brightness cannot be satisfactorily resolved with the currently available standard systems across all areas.

Approaches have been presented indicating how the particular challenges can be met in high mountain regions. This includes oblique perspectives with off-nadir angles of more than $75^{\circ}$, so that steep slopes can be imaged with high GSDs and very detailed DEMs/DSMs can be created. A High Dynamic Range (HDR) mode should make possible the imaging of all occurring lighting situations. This mode means that an increase of the imaging dynamic range from 12 to 16 bits can be expected.

The 3D aerial camera system MACS-Himalaya has been presented. It is optimised for use in high mountains. In conjunction with a suitable aircraft, here demonstrated with a Stemme S10-VTX, image data can be generated under operational conditions for high resolution DEMs/DSMs of, amongst other structures, glaciers, steep slopes and entire mountainous regions. As part of an expedition to Nepal, the system was successfully operated at altitudes of $9,200 \mathrm{~m}$ in open air conditions. The regions Kali-Gandaki Valley, Seti Valley, Rikha-Samba Glacier and Khumbu Glacier/Mt. Everest were subject to systematic survey flights. Photographs were taken to evaluate the camera system and to be able to determine the potential of the methodology. Moreover, photographs were taken to form a first database for applications relating to natural disaster and glacier monitoring.

Exemplary, mountain sides were represented with a GSD of $12 \mathrm{~cm}$ (individual aerial photograph, slope gradient $>70^{\circ}$ ) and $15 \mathrm{~cm}$ (dense point cloud, slope gradient approximately $50^{\circ}$ ). Based on high contrast areas, saturation zones were used to highlight the fact that in spite of optimum exposure, the dynamic range of the sensor modules is considerably too narrow. The existing brightness differences cannot always be imaged using the available dynamic range of the sensor. HDR by exposure bracketing make all areas of such a scene visible.

The systematic work on HDR and on consideration of extreme oblique perspectives will shortly be completed. The geometric evaluation is in progress and likewise will be published in the near future.

The presented statements indicate that based on the illustrated approaches DEMs and DSMs can be prepared for mountainous regions at all possible altitudes and that their geometric and radiometric resolution will be significantly higher than has been possible up until now. The evaluation continues.

\section{ACKNOWLEDGEMENTS}

Thanks are owed to Professor P. Dahmann of Aachen University of Applied Sciences, Aerospace Engineering Department, who was instrumental in procuring the Stemme S10-VTX research aircraft for the project. Thanks goes to the Mountain Wave Project (MWP) who were responsible for project organisation in Nepal and the idea of the Mt. Everest 
survey flight (René Heise and Klaus Ohlmann). A special thanks to the two pilots Klaus Ohlmann (PIC) and Jona Keimer, who piloted all the flights in Nepal. Finally, very special thanks are owed to the whole team of DLR OS-ASK who assembled, software engineered and post-processed all data.

\section{REFERENCES}

Abermann, J., Fischer, A., Lambrecht, A., Geist T., 2010. On the potential of very high-resolution repeat DEMs in glacial and periglacial environments. The Cryosphere, 4, 53-65.

Altherr, W. \& Grün, A., 1990. The new 1:50,000 map of Mount Everest. Colonel Sir George Everest CB FRS, Proceedings of the Bicentenary Conference at the Royal Geographical Society, November 8th, London, 68-75.

Bamber, J.L. \& Rivera, A., 2007. A review of remote sensing methods for glacier mass balance determination. Global Planetary Change, 59 (1-4), 138-148.

Berthier, E., Vincent, C., Magnússon, E., Gunnlaugsson, A.P., Pitte, P.,Le Meur, E., Masiokas, M., Ruiz, L., Pálsson, F., Belart, J. M. C., Wagnon, P., 2014: Glacier topography and elevation changes derived from Pléiades sub-meter stereo images. The Cryosphere, 8, 2275-2291, doi:10.5194/tc-8-2275-2014.

Bhandary, N.P., Dahal, R.K., Okamura, M., 2012. Preliminary Understanding of the Seti River Debris-Flood in Pokhara, Nepal, on May 5th, 2012. ISSMGE Bulletin, 6 (4), 8-18.

Bolch, T., Pieczonka, T., Benn, D.I., 2011. Multi-decadal mass loss of glaciers in the Everest area (Nepal Hamalaya) derived from stereo imagery. The Cryosphere, 5, 349-358, doi:10.5194/tc-5349-2011.

Heise, R., Brauchle, J., Dahmann, P., Junkermann, W., Ledderhos, C., 2014. The MWP-Himalaya Research Expedition Challenges, Objectives and the First Scientific Results of this Outstanding Airborne Measurement Campaign in Nepal. In: XXXII. OSTIV Congress Leszno 2014 Abstract Book, ISBN 978-6054303359.

Honkavaara, E. \& Markelin, L., 2007. Radiometric Performance of Digital Image Data Collection - A Comparison of ADS40/DMC/UltraCam and EmergeDSS. In: Photogrammetric Week 2007, edited by: Dieter Fritsch, 117-129.

ICIMOD, 2011. Glacial lakes and glacial lake outburst floods in Nepal. Kathmandu, Nepal, 99 pages, ISBN 97892911519.

Immerzeel, W.W., Kraaijenbrink, P.D.A., Shea, J.M., Shrestha, A.B., Pellicciotti, F., Bierkens, M.F.P., de Jong, S.M., 2014. High-resolution monitoring of Himalayan glacier dynamics using unmanned aerial vehicles. In: Remote Sensing of Environment, $\quad 150 \quad$ (2014) 93-103, doi:10.1016/j.rse.2014.04.025.

Jacobsen, K., 2005. High Resolution Satellite Imaging Systems Overview. In: PFG - Photogrammetrie, Fernerkundung, Geoinformation, 2005 (6), 487-496.

Kääb, A., 2002. Monitoring high-mountain terrain deformation from repeated air- and spaceborne optical data: examples using digital aerial imagery and ASTER data. ISPRS Journal of Photogrammetry and Remote Sensing, 57 (1-2), 39-52, doi:10.1016/S0924-2716(02)00114-4.

Korona, J., Berthier, E., Bernard, M., Rémy, F., Thouvenot, E., 2009. SPIRIT. SPOT 5 stereoscopic survey of Polar Ice: Reference Images and Topographies during the fourth International Polar Year (2007-2009). ISPRS Journal of Photogrammetry and Remote Sensing, 64 (2), 204-212, doi:10.1016/j.isprsjprs.2008.10.005.
Lehmann, F., Berger, R., Brauchle, J., Hein, D., Meissner, H., Pless, S., Strackenbrock, B., Wieden, A., 2011: MACS Modular Airborne Camera System for Generating Photogrammetric High-Resolution Products. In: PFG, 2011 (6), 435-446.

Lemke, P., Ren, J., Alley, R.B., Allison, I., Carrasco, J., Flato, G., Fujii, Y., Kaser, G., Mote, P., Thomas, R.H., Zhang, T., 2007: Observations: Changes in Snow, Ice and Frozen Ground. In: Climate Change 2007: The Physical Science Basis. Contribution of Working Group I to the Fourth Assessment Report of the Intergovernmental Panel on Climate Change, 337-383, Cambridge University Press, Cambridge, United Kingdom and New York, NY, USA.

Müller, J., Gärtner-Roer, I., Thee, P., Ginzler, Ch., 2014. Accuracy assessment of airborne photogrammetrically derived highresolution digital elevation models in a high mountain environment. ISPRS Journal of Photogrammetry and Remote Sensing, 98 (2014), 58-69, doi:10.1016/j.isprsjprs.2014.09.015.

Pieczonka, T., Bolch, T., Buchroithner, M., 2011. Generation and evaluation of multitemporal digital terrain models of the Mt. Everest area from different optical sensors. ISPRS Journal of Photogrammetry and Remote Sensing, 66 (6), 927-940, doi:10.1016/j.isprsjprs.2011.07.003.

Poli, D., Remondino, F., Angiuli, E., Agugiaro G., 2014. Radiometric and geometric evaluation of GeoEye-1, WorldView-2 and Pléiades-1A stereo images for 3D information extraction. ISPRS Journal of Photogrammetry and Remote Sensing, 100 (2015), 35-47, doi:10.1016/j.isprsjprs.2014.04.007.

Poli, D., Angiuli E., Remondino, F., 2010. Radiometric and geometric analysis of WorldView-2 stereo scenes. In: International Archives of Photogrammetry, Remote Sensing and Spatial Information Sciences, Proceedings of the ISPRS Commission I Mid-Term Symposium "Image Data Acquisition Sensors \& Platforms", Calgary, AB, Canada, 2010; 38. Part 1.

Quincey, D.J., Lucas, R.M., Richardson, S.D., Glasser, N.F., Hambrey, M.J., Reynolds, J.M., 2005. Optical remote sensing techniques in high-mountain environments: application to glacial hazards. In: Progress in Physical Geography, December 2005, 29 (4), 475-505, doi: 10.1191/0309133305pp456ra.

Raup, B.H., Kieffer, H.H., Hare, T.M., Kargel, J.S., 2000. Generation of Data Acquisition Requests for the ASTER Satellite Instrument for Monitoring a Globally Distributed Target: Glaciers. IEEE Transactions on Geoscience and Remote Sensing, 38 (2), 1105-1112.

Schneider, S. \& Gruber, M., 2008. Radiometric Quality of Ultracam-X Images. The International Archives of the Photogrammetry, Remote Sensing and Spatial Information Sciences. Vol. XXXVII. Part B1, Beijing, China.

Schwanghart, W., Bernhardt , A., Stolle, A., Adhikari, B. \& Korup, A., 2014. Reassessing Catastrophic Infill of the Pokhara Valley, Nepal Himalaya. Geophysical Research Abstracts Vol. 16, EGU2014-15787, May 2014.

Stumpf, A., Malet, J.-P., Allemand P.,Ulrich P., 2014. Surface reconstruction and landslide displacement measurements with Pléiades satellite images. ISPRS Journal of Photogrammetry and Remote Sensing, $95 \quad$ (2014), $1-12$, doi:10.1016/j.isprsjprs.2014.05.008.

Toutin, T., 2002. Three-Dimensional Topographic Mapping With ASTER Stereo Data in Rugged Topography. IEEE Transactions on Geoscience and Remote Sensing, 40 (10), 2241-2247.

Wieden, A. \& Stebner, K., 2013. Referenzorientierung für Bilddaten aus Mehrkopfkamerasystemen. In: DGPF Tagungsband 22 / 2013, 518-525., Freiburg, ISSN 0942-2870. 